\title{
SZACOWANIE DYSPROPORCJI W AKTYWNOŚCI PATENTOWEJ PAŃSTW OECD Z WYKORZYSTANIEM METOD PRZESTRZENNO-CZASOWYCH
}

\begin{abstract}
Z a r y s t r e ś c i. W artykule przedstawiono możliwość zastosowania próby panelowej i modelowania w oparciu o nią jako metody wyznaczenia wskaźników aktywności patentowej. Badanie przeprowadzono z wykorzystaniem danych dla państw europejskich. Otrzymane wyniki w zestawieniu z zastosowaną metodologią uwzględniającą nowoczesne podejście do badania stacjonarności i kointegracji dla prób panelowych, wskazują na użyteczność stosowanych metod.
\end{abstract}

S ło w a k 1 u c z o w e: aktywność patentowa, model panelowy, dekompozycja wyrazu wolnego.

\section{WSTĘP}

W coraz częściej poruszanym przez ekonomistów temacie innowacji pojawia się wiele sposobów pomiaru. W ujęciu makroekonomicznym - ze względu na wymogi dotyczące długości szeregów - często korzysta się z prób przestrzenno-czasowych czy panelowych. Jako ich zaletę można wymienić, obok samego umożliwienia prowadzenia badań, możliwość uzyskania porównywalnych dla różnych obiektów ocen wynikających z dekompozycji składnika losowego lub wyrazu wolnego. Niniejsze badania związane są bezpośrednio z patentami opartymi na wynalazkach rozumianych jako „oryginalna koncepcja technicznej innowacji, w której zawarta jest teoretyczna możliwość działania" (Budnikowski, 1995). Aktywność patentowa jest jednym z bardziej dostępnych mierników aktywności innowacyjnej ze względu na możliwość pozyskiwania $\mathrm{w}$ miarę porównywalnych danych wynikających z usankcjonowanego prawnie trybu zarówno przyjmowania jak i nadawania patentów. Dostępne informacje pochodzą głownie z Word Intellectual Property Organizations (WIPO) i European Patent Office (EPO). Abstrahując od charakteru zmiennych objaśniających równanie wyjaśniające aktywność patentową przy wykorzystaniu danych panelowych umożliwia otrzymanie, w skutek dekompozycji, swojego rodzaju 
wskaźników aktywności patentowej. Różnice pomiędzy tymi wartościami oddziałują w sposób bezpośredni na wartości teoretyczne zmiennej objaśnianej (w zależności od postaci modelu addytywnie lub multiplikatywnie) dywersyfikując jej wartość dla różnych obiektów przy tych samych założeniach podstawowych.

\section{ZAŁOŻENIA}

W prezentowanym badaniu przyjęto następujące założenia:

- miernikiem aktywności patentowej jest liczba patentów zgłoszonych do EPO w przeliczeniu na tysiąc osób aktywnych zawodowo,

- determinantami aktywności patentowej są nakłady brutto na działalność $\mathrm{B}+\mathrm{R}$ oraz badacze zatrudnieni $\mathrm{w}$ działalności $\mathrm{B}+\mathrm{R}$,

- próba ma charakter przekrojowo-czasowy, przy czym dane dotyczą okresów z lat 1995-2005 i państw europejskich należących do OECD (oraz Łotwy i Estonii); wykorzystanie dłuższych szeregów jest z jednej strony niemożliwe - brak danych, $\mathrm{z}$ drugiej pojawia się niebezpieczeństwo zakłócenia obecnych relacji przez dokonane zmiany systemowe, zwłaszcza w środkowo wschodniej części Europy,

- dopuszcza się możliwość interpolacji w przypadku pojawienia się incydentalnych braków danych lub rzadszej niż roczna powtarzalności gromadzonych wyników. W zależności od kształtu badanego procesu wykorzystuje się metodę odcinkową lub trend o odpowiednim dopasowaniu i jednocześnie możliwie najprostszej postaci analitycznej (dotyczy zwłaszcza stopnia wielomianu),

- dane źródłowe pochodzące z opracowań EUROSTAT, OECD, WIPO i narodowych biur statystycznych nie są korygowane bezpośrednio w przypadku domniemania błędów lub nieścisłości.

\section{OBLICZENIA WSTĘPNE}

W pierwszym etapie pod uwagę wzięto szeregi przestrzenno-czasowe, które miały stanowić podstawę budowy modelu. Szeregi te zostały zbadane pod względem ewentualnej niestacjonarności, gdyż ich długość - 11 okresów - poniekąd obliguje nas do tego. Tym bardziej, że wnioski oparte na obliczeniach końcowych chcemy traktować jako niezależne od czynnika czasowego. Zakładając zgodnie $\mathrm{z}$ teorią, iż $\mathrm{w}$ związku $\mathrm{z}$ ekonomicznym i przy okazji rocznym charakterem danych, ich poziom zintegrowania jest nie wyższy niż 2 (Gruszczyński, 2003), w badaniach wstępnych zaproponowano przetestowanie pozio$\mathrm{mu}$ integracji dla wskazanych zmiennych. W tym celu wykorzystano procedury zawarte w pakiecie Eviews, umożliwiające względnie szybką ocenę ewentualnego braku stacjonarności lub ocenę stopnia poziomu integracji. Zgodnie 
z możliwościami programu w poniższych tabelach przedstawiono wyniki kilku testów pierwiastka jednostkowego wskazujących na istnienie stopnia integracji.

Tabela 1. Wyniki testów pierwiastka jednostkowego dla badanych zmiennych na poziomach $\mathrm{I} \sim(0)$

\begin{tabular}{|c|c|c|c|c|c|}
\hline \multirow[b]{2}{*}{ Zmienna } & \multirow[t]{2}{*}{ Estymator: } & \multicolumn{2}{|l|}{ Newey-West } & \multicolumn{2}{|l|}{ Andrews } \\
\hline & & Statystyka & $p$-value & Statystyka & $\mathrm{p}$-value \\
\hline \multirow{4}{*}{ PET } & Levin, Lin \& Chu t* & $-7,17081$ & 0,0000 & $-7,00580$ & 0,0000 \\
\hline & Im, Pesaran and Shin W- statystyka & $-1,99990$ & 0,0228 & $-1,99990$ & 0,0228 \\
\hline & ADF - Fisher $X^{2}$ & 69,8771 & 0,0331 & 69,8771 & 0,0331 \\
\hline & PP - Fisher $X^{2}$ & 118,777 & 0,0000 & 83,3070 & 0,0022 \\
\hline \multirow{4}{*}{ GERD } & Levin, Lin \& Chu t* & $-1,19290$ & 0,1165 & $-8,45100$ & 0,0000 \\
\hline & Im, Pesaran and Shin W- statystyka & 0,85439 & 0,8036 & $-5,45590$ & 0,0000 \\
\hline & ADF - Fisher $X^{2}$ & 51,6001 & 0,4110 & 123,319 & 0,0000 \\
\hline & PP - Fisher $X^{2}$ & 54,5887 & 0,3044 & 121,365 & 0,0000 \\
\hline \multirow{4}{*}{$\mathrm{RECH}$} & Levin, Lin \& Chu t* & $-3,02711$ & 0,0012 & $-9,59271$ & 0,0000 \\
\hline & Im, Pesaran and Shin W- statystyka & 1,67520 & 0,9531 & $-5,52320$ & 0,0000 \\
\hline & ADF - Fisher $X^{2}$ & 39,2213 & 0,8641 & 120,326 & 0,0000 \\
\hline & PP - Fisher $X^{2}$ & 42,0529 & 0,7804 & 117,931 & 0,0000 \\
\hline
\end{tabular}

*test zakłada wspólny pierwiastek jednostkowy, pozostałe zakładają indywidualne pierwiastki jednostkowe.

Źródło: obliczenia własne.

Prawdopodobieństwa dla testu $\mathrm{F}$ wyznaczono wykorzystując asymptotyczny rozkład $\chi^{2}$, pozostałe prawdopodobieństwa wyznaczono zgodnie $\mathrm{z}$ rozkładem asymptotycznie normalnym.

Dla zmiennej endogenicznej zgodnie z wynikami wszystkich testów wskazalibyśmy na stacjonarność. Pozostałe zmienne charakteryzują się innymi wynikami, zwłaszcza przy zastosowaniu estymatora Newey`a-Westa. Estymator Andrews, a z kolei daje dużo bardziej optymistyczne rezultaty, czego można było się spodziewać biorąc pod uwagę test PP i dotychczasowe badania przeprowadzone przez Yin-Wong Cheung i Kon S. Lai (1997). Zwracając jednak uwagę na ewentualne istnienie pierwiastków jednostkowych, możemy przyjąć, iż zmienne nasze są zintegrowane w stopniu 1, I (1). Tym bardziej, że w tym zakresie wyniki wszystkich testów są zgodne. Przyjmując zatem poziom integracji wspólny dla wszystkich zmiennych, podejmujemy próbę przetestowania istnienia kointegracji w założonym układzie czyli równania ze zmienną PET w postaci objaśnianej i GERD i RECH w postaci objaśniających.

Estymacja z wykorzystaniem programu Eviews daje, możliwość uzyskania (w przypadku zastosowania wyników sumarycznych) oceny statystyk dla siedmiu testów. Wykorzystanie tych testów jest jednak o tyle trudne, iż mogą one (i tak dzieje się w naszym przypadku) dawać rezultaty o odmiennym wyniku. Związane jest to z rozmiarami zastosowanego panelu. Pedroni (2004), który ba- 
dał tego typu zjawiska z wykorzystaniem symulacji Monte Carlo wskazał, iż stosowanie testów panelowego-v i grupowego - rho daje wręcz złe wyniki w przypadku, gdy długość szeregu czasowego w panelu jest mniejsza niż 20 obserwacji. W takiej sytuacji, jako bardziej trafne przewiduje się stosowanie testów grupowego - ADF i panelowego - ADF.

Tabela 2. Wyniki testów pierwiastka jednostkowe dla badanych zmiennych na poziomach $\mathrm{I} \sim(1)$

\begin{tabular}{|c|c|c|c|c|c|}
\hline \multirow[b]{2}{*}{ Zmienna } & \multirow[b]{2}{*}{ Metoda: } & \multicolumn{2}{|l|}{ Newey-West } & \multicolumn{2}{|l|}{ Andrews } \\
\hline & & Statystyka & p-value & Statystyka & $p$-value \\
\hline \multirow{4}{*}{ PET } & Levin, Lin \& Chu t* & $-10,2833$ & 0,0000 & $-10,4350$ & 0,0000 \\
\hline & Im, Pesaran and Shin W- statystyka & $-6,2851$ & 0,0000 & $-6,2851$ & 0,0000 \\
\hline & ADF - Fisher $X^{2}$ & 133,2590 & 0,0000 & 133,2590 & 0,0000 \\
\hline & PP - Fisher $X^{2}$ & 150,2810 & 0,0000 & 142,5140 & 0,0000 \\
\hline \multirow{4}{*}{ GERD } & Levin, Lin \& Chu t* & $-9,7824$ & 0,0000 & $-8,4510$ & 0,0000 \\
\hline & Im, Pesaran and Shin W- statystyka & $-5,4559$ & 0,0000 & $-5,4559$ & 0,0000 \\
\hline & ADF - Fisher $X^{2}$ & 123,3190 & 0,0000 & 123,3190 & 0,0000 \\
\hline & PP - Fisher $X^{2}$ & 144,5690 & 0,0000 & 121,3650 & 0,0000 \\
\hline \multirow{4}{*}{$\mathrm{RECH}$} & Levin, Lin \& Chu t* & $-11,0622$ & 0,0000 & $-9,5927$ & 0,0000 \\
\hline & Im, Pesaran and Shin W- statystyka & $-5,52320$ & 0,0000 & $-5,52320$ & 0,0000 \\
\hline & ADF - Fisher $X^{2}$ & 120,326 & 0,0000 & 120,326 & 0,0000 \\
\hline & PP - Fisher $X^{2}$ & 131,282 & 0,0000 & 117,931 & 0,0000 \\
\hline
\end{tabular}

Źródło: obliczenia własne.

Rezultaty badań wskazały na następujące wartości testów.

Tabela 3. Wyniki testów kointegracji reszt Pedroniego dla modelu na zmiennych PET GERD RECH

\begin{tabular}{|c|c|c|c|c|}
\hline $\begin{array}{r}\text { Testy z hipotezą alternatywną o } \\
\text { Rodzaj modelu }\end{array}$ & \multicolumn{2}{|c|}{ Bez trendu } & \multicolumn{2}{|c|}{ Bez trendu i wyrazu wolnego } \\
\hline Typ testu & Statystyka & $\mathrm{p}$-value & Statystyka & $\mathrm{p}$-value \\
\hline Panelowa v-Statystyka & $-0,8536$ & 0,8033 & 0,9798 & 0,1636 \\
\hline Panelowa rho-Statystyka & 2,3876 & 0,9915 & 0,3700 & 0,6443 \\
\hline Panelowa PP-Statystyka & $-0,0985$ & 0,4608 & $-1,7103$ & 0,0436 \\
\hline Panelowa ADF-Statystyka & $-0,4230$ & 0,3361 & $-1,8798$ & 0,0301 \\
\hline \multicolumn{5}{|c|}{ Testy z hipotezą alternatywną o współczynniku AR międzygrupowym } \\
\hline Typ testu & Statystyka & p-value & Statystyka & $\mathrm{p}$-value \\
\hline Grupowa rho-Statystyka & 3,0116 & 0,9987 & 1,9235 & 0,9728 \\
\hline Grupowa PP-Statystyka & $-5,0759$ & 0,0000 & $-3,5982$ & 0,0002 \\
\hline Grupowa ADF-Statystyka & $-2,5234$ & 0,0058 & $-3,4899$ & 0,0002 \\
\hline
\end{tabular}

Źródło: obliczenia własne. 
Jedynie wyniki oparte na testach ,grupowych” - uznawanych za posiadające większą siłę niż ,panelowe” przy badaniach na próbach o mniejszych rozmiarach (por. Pedroni, 1995) - daje wskazanie na istnienie kointegracji. W ujęciu wykluczającym istnienie wyrazu wolnego (wspólnego), testy oparte na statystyce $\mathrm{v}$ i rho dają wyniki niepożądane $\mathrm{z}$ punktu widzenia niniejszych badań (brak podstaw do odrzucenia hipotezy $\mathrm{H}_{0}$ ). Jednak biorąc pod uwagę spostrzeżenia Pedroniego, za właściwsze uznajemy wyniki testów ADF, co z kolei wskazuje na hipotezę $\mathrm{H}_{1}$ - mówiącą o istnieniu wektora kointegrującego. Warto również zwrócić uwagę na test PP, który także daje rezultat pożądany. Należy pamiętać, iż testy „grupowe” w odróżnieniu od „panelowych” zakładają, że współczynniki autoregresji nie muszą mieć charakteru jednorodnego w ujęciu wszystkich obiektów (Hsu-Ling i inni, 2008). Przyjmując więc słabą moc testu grupowegorho, pozostałe testy grupowe dają nam wskazanie na istnienie kointegracji w obu ujęciach, modelowych.

Uzyskane rezultaty nie dają badaczowi możliwości podjęcia jednoznacznej decyzji. Z jednej strony możemy założyć, że wektor kointegrujący istnieje, jeżeli pominiemy wyraz wolny w naszym modelu. Pamiętać jednak należy również, iż model ten ze względu na swą konstrukcję panelową, posiadał będzie zdekomponowany wyraz wolny, który w zależności od istotności poszczególnych jego części będzie kompletny (tożsamy z wyrazem wolnym) lub będzie synonimem kilku zawartych $w$ modelu zmiennych zero-jedynkowych. $Z$ drugiej strony wykorzystanie faktu, iż z racji stacjonarności zmienną PET uznać możemy również za zintegrowaną w stopniu pierwszym, jest pewnym nadużyciem. W związku ze wskazanymi wątpliwościami dotyczącymi braku jednoznaczności co do istnienia relacji kointegrujących jako rozwiązanie zaproponowano zastosowanie modelu z korektą błędem, który w takim przypadku jest jednym z popularniejszych narzędzi (Strzała, 2005). Jego dodatkową zaletą jest fakt uwzględnienia zarówno krótkoterminowych jak i długoterminowych elastyczności zamiennej endogenicznej względem czynników ją determinujących. Dzięki temu dekomponowane wyrazy wolne, których interpretacja w niniejszym ujęciu stanowi podstawę badań, jest bardziej precyzyjna. Ewentualne czynniki o charakterze dynamicznym uwidaczniają bowiem swój wpływ w większym stopniu $\mathrm{w}$ ocenach parametrów strukturalnych stojących przy zmiennych objaśniających.

Biorąc pod uwagę domniemanie kształtu prezentowanych zależności (Szajt, 2006), zaproponowano wstępnie model następującej postaci:

$$
\begin{aligned}
& \triangle \log P A T A_{i t}=\alpha^{\prime}{ }_{i}+\left(\rho_{I}-1\right)\left(\log P A T A_{i t-1}-\delta_{1} \log G E R D P_{i t-1}-\delta_{2} \log R E C H A_{i t-1}\right) \\
& +\gamma_{4} \Delta \log \beta_{1} G E R D P_{i t}+\gamma_{5} \Delta \log \beta_{2} R E C H A_{i t}+\xi_{i t}
\end{aligned}
$$

gdzie:

$a_{i}^{\prime}$ oszacowywany jest jako wyraz wolny zdekomponowany na $i=25$ obiektów - państw,

$P A T A_{i t}$ - liczba patentów zgłoszonych przez rezydentów na terenie danego państwa $\boldsymbol{i}$ w przeliczeniu na liczbę aktywnych zawodowo w okresie $t$, 
$G E R D P_{i t}$ - wydatki brutto na działalność $\mathrm{B}+\mathrm{R}$ w przeliczeniu na personel $\mathrm{B}+\mathrm{R} w$ ekwiwalencie pełnego czasu zatrudnienia w państwie $i \mathrm{w}$ okresie $t$

RECHA $A_{i t}$ - zatrudnieni na stanowiskach badawczych według ekwiwalentu pełnego zatrudnienia $\mathrm{w}$ przeliczeniu na liczbę aktywnych zawodowo $\mathrm{w}$ państwie $i$ w okresie $t$,

\section{WYNIKI}

Zgodnie z przyjętymi założeniami oszacowany model charakteryzował się postacią potęgową przy pełnej dekompozycji wyrazu wolnego. Ze względu na różnice $\mathrm{w}$ kierunkach zależności pomiędzy poszczególnymi kategoriami, do próby końcowej zakwalifikowano 16 państw. Estymacji dokonano z wykorzystaniem programu Gretl. Na wstępie - zgodnie z teorią - zastosowano test na zróżnicowanie wyrazu wolnego. Statystyka testu $\mathrm{F}_{(15,140)}=3,8146 \mathrm{z}$ wartością $\mathrm{p}=1,15252 \mathrm{e}-005$ potwierdza zasadność estymacji modelu panelowego $\mathrm{z}$ efektami ustalonymi. W toku estymacji, jako zmienna nieistotna statystycznie, ze zbioru zmiennych objaśniających została usunięta GERD $\mathrm{t}_{\mathrm{t}-1}$. Otrzymane rezultaty prezentuje tabela.

Tabela 4. Wartości ocen parametrów modelu w postaci potęgowej

\begin{tabular}{|l|c|c|c|c|}
\hline \multicolumn{1}{|c|}{$\mathrm{Zmienna}$} & Parametr & Ocena parametru & Statystyka $\mathrm{t}$ & p-value \\
\hline $\mathrm{PETA}_{\mathrm{i}, \mathrm{t}-1}$ & $\alpha_{1}$ & 0,5683 & $-6,9836$ & 0,0000 \\
\hline $\mathrm{RECHA}_{\mathrm{i}, \mathrm{t}-\mathrm{t}}$ & $\delta_{2}$ & 0,7809 & 1,9086 & 0,0584 \\
\hline$\Delta \mathrm{GERDP}_{\mathrm{i}, \mathrm{t}}$ & $\beta_{1}$ & 1,0802 & 3,5093 & 0,0006 \\
\hline$\Delta \mathrm{RECHA}_{\mathrm{i}, \mathrm{t}}$ & $\beta_{2}$ & 0,7617 & 2,6235 & 0,0097 \\
\hline $\mathrm{BE}_{\mathrm{t}}$ & $\alpha_{B E}$ & 0,3060 & $-2,9727$ & 0,0035 \\
\hline $\mathrm{CZ} \mathrm{t}$ & $\alpha_{C Z}$ & 0,1137 & $-5,1812$ & 0,0000 \\
\hline $\mathrm{DK}_{\mathrm{t}}$ & $\alpha_{D K}$ & 0,2999 & $-2,9377$ & 0,0039 \\
\hline $\mathrm{DE}_{\mathrm{t}}$ & $\alpha_{D E}$ & 0,4010 & $-2,5089$ & 0,0133 \\
\hline $\mathrm{EE}_{\mathrm{t}}$ & $\alpha_{E E}$ & 0,0767 & $-5,0538$ & 0,0000 \\
\hline $\mathrm{IE}_{\mathrm{t}}$ & $\alpha_{I E}$ & 0,2281 & $-3,8027$ & 0,0002 \\
\hline $\mathrm{FR}_{\mathrm{t}}$ & $\alpha_{F R}$ & 0,3007 & $-3,0255$ & 0,0030 \\
\hline $\mathrm{LV}_{\mathrm{t}}$ & $\alpha_{L V}$ & 0,0709 & $-5,4952$ & 0,0000 \\
\hline $\mathrm{HU}_{\mathrm{t}}$ & $\alpha_{H U}$ & 0,1259 & $-5,1246$ & 0,0000 \\
\hline $\mathrm{NL}_{\mathrm{t}}$ & $\alpha_{N L}$ & 0,3877 & $-2,8611$ & 0,0049 \\
\hline $\mathrm{AT}_{\mathrm{t}}$ & $\alpha_{A T}$ & 0,3329 & $-3,0377$ & 0,0028 \\
\hline $\mathrm{PL}_{\mathrm{t}}$ & $\alpha_{P L}$ & 0,0597 & $-5,3160$ & 0,0000 \\
\hline $\mathrm{PT}_{\mathrm{t}}$ & $\alpha_{P T}$ & 0,0853 & $-5,2087$ & 0,0000 \\
\hline $\mathrm{Fl}_{\mathrm{t}}$ & $\alpha_{F I}$ & 0,2972 & $-2,4965$ & 0,0137 \\
\hline $\mathrm{SE}_{\mathrm{t}}$ & $\alpha_{S E}$ & 0,3160 & $-2,6370$ & 0,0093 \\
\hline $\mathrm{NO}_{\mathrm{t}}$ & $\alpha_{N O}$ & 0,1891 & $-3,3407$ & 0,0011 \\
\hline
\end{tabular}


Źródło: obliczenia własne.

Trzeba zauważyć, że wszystkie oceny dotyczące dekomponowanych wyrazów wolnych są wysoce istotne statystycznie, a więc wnioskowanie na ich podstawie - co jest w dużej mierze celem niniejszej estymacji - jest wyraźnie usankcjonowane metodologicznie. Jest to tym ważniejsze, że w związku z potęgowym kształtem funkcji, wyraz wolny wchodzi do niej multiplikatywnie.

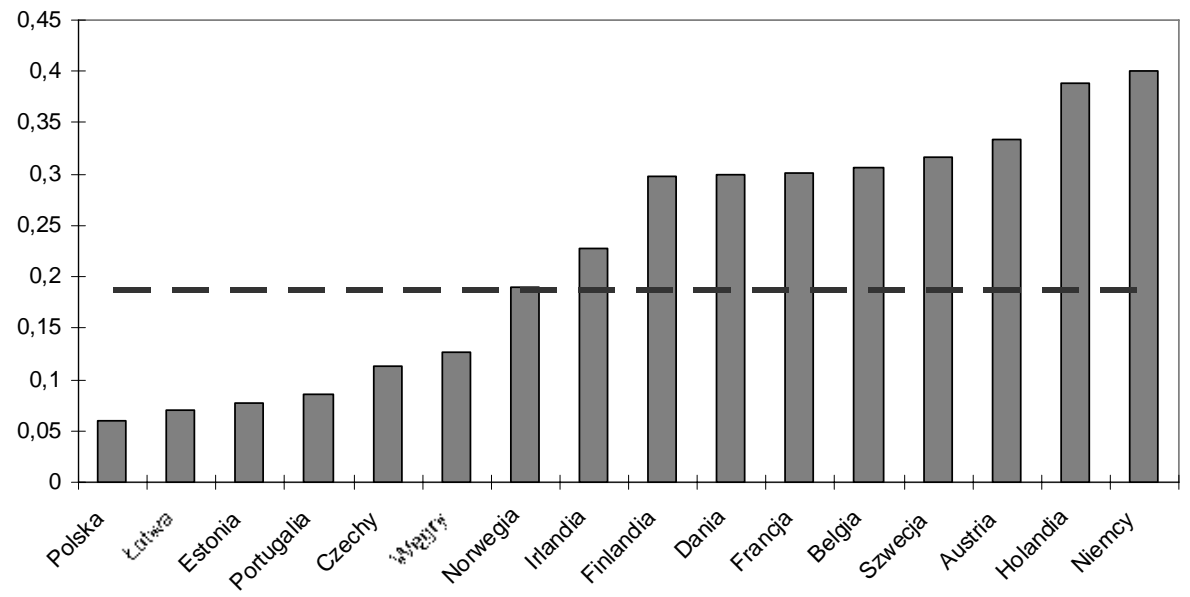

Wykres 1. Wartości ocen zdekomponowanych wyrazów wolnych dla poszczególnych państw

Źródło: opracowanie własne na podstawie tabeli 4.

Zaprezentowany na wykresie stały poziom 0,1873 jest odzwierciedleniem oszacowanego próbnie wspólnego wyrazu wolnego (odpowiednika średniego poziomu aktywności patentowej) dla całej grupy. Na tym tle państwa takie jak Niemcy czy Holandia jawiły by się jako absolutni liderzy, podczas, gdy Polska Łotwa i Estonia to outsiderzy. Reperkusje tych stwierdzeń są bardzo ważne. W praktyce bowiem, przy jednakowych nakładach poszczególnych czynników determinujących aktywność patentową, różnica reakcji końcowej - w długim okresie - będzie zbliżona do różnic przedstawionych na wykresie. Można zatem mówić o bardzo wysokiej lub niskiej aktywności patentowej poszczególnych państw.

Jak widać, ta prosta (w ujęciu konstrukcji próby panelowej) metoda pozwala na uzyskanie bardzo wartościowych i co ważne porównywalnych wskaźników. Co również nie jest bez znaczenia, ich oszacowania zwykle nie są silnie wrażliwe na zmiany ocen głównych determinant badanego procesu. W skrajnych przypadkach obok wartości charakterystycznych możemy co najwyżej uzyskać wartości „typowe” reprezentowane przez wspólny wyraz wolny. 


\title{
LITERATURA
}

Budnikowski F. (1995), Ekonomia Innowacje ekonomiczne $w$ gospodarce narodowej, OWPR, Rzeszów.

Gruszczyński M., Podgórska M. (2004), Ekonometria, Oficyna Wydawnicza SGH, Warszawa.

Hsu-Ling Ch., Yahn-Shir Ch., Chi-Wei S., Ya-Wen Ch. (2008) The Relationship between Stock Price and EPS: Evidence Based on Taiwan Panel Data, „Economics Bulletin”, Vol. 3, No. 30.

Pedroni P. (2004), Panel Cointegration:Asymptotic and Finite Sample Properties of Pooled Time Series Tests With an Application to The Ppp Hypothesis, „Econometric Theory”, 20, 597 -625 .

Pedroni P. (1995), Panel cointegration, asymptotic and finite sample properties of pooled time series tests, with an application to the PPP hypothesis, Indiana University, Working Paper in Economics, No. 95-031, June.

Strzała K. (2005), Korelacja inwestycji i oszczędności w krajach Unii Europejskiej - weryfikacja empiryczna z zastosowaniem podejścia panelowego, Prace i Materiały Wydziału Zarządzania UG - „Ekonometryczne modelowanie i prognozowanie wzrostu gospodarczego" nr 1, Gdańsk, s. 141-157.

Szajt M. (2006), Modeling of State Innovativeness Based on Space-time Models, w: „Dynamic Econometric Models" Vol. 7, UMK w Toruniu, Toruń, s. 231-238.

Yin-Wong Ch., Kon S. L. (1997), Bandwidth selection, prewhitening, and the power of the Phillips-Perron test, „Econometric Theory”, 13, Cambridge University Press, 679-691.

\section{ESTIMATION OF DISPROPORTIONS IN PATENT ACTIVITY OF OECD COUNTRIES USING SPATIO-TEMPORAL METHODS}

\begin{abstract}
A b s t r a c t. The article contains a presentation of possibility of using panel-based sample and modeling based on this sample as methods of determining indicators of patent activity. The research was conducted with the help of data from European countries. Results in association with used methodology which takes into account modern approach to stationary and cointegration for panel-based samples, indicate the usefulness of applied methods.
\end{abstract}

K e y w o r d s: patent activity, panel model, decomposition of constant term. 